\title{
APPLY GIS AND REMOTE SENSING FOR CITY DESIGNING AND ADMINISTRATION
}

\author{
Saragadam Sushma \\ Lecturer, Sagi Ramakrishnam Raju Engineering College, A.P., India. \\ saragadamsushma203@gmail.com
}

\begin{abstract}
Keywords: GIS, City planning, GIS data management, Geographic Information Policy and Standards, Urban Planning and development, Spatial data,Tthematic mapping, Aerial photography, Urban planners.
\end{abstract}

\begin{abstract}
A B S T R A C T
The land data framework (GIS) is an apparatus utilized by and large for any $P C$ based capacity for controlling topographical information. The equipment and programming elements of GIS incorporate information input, information stockpiling, information administration (information control, refreshing, evolving, trade) and information announcing (recovery, introduction, examination, blend, and so on.) We all realize that a few GIS will bomb, notwithstanding, when disappointment does happen and a re-evaluation is played out, the exercises can be distributed with the goal that different clients may benefit from the experience. This paper evaluates the GIS usage in city arranging; it distinguishes the explanations behind its present disappointment and recommends courses for a fruitful execution that could be all the more for the most part relevant, particularly in creating and created nations.
\end{abstract}

Citation: Saragadam Sushma (2018). Apply Gis And Remote Sensing For City Designing and Administration.International Journal of Advanced Multidisciplinary Scientific Research (IJAMSR ) ISSN:2581-4281 Vol 1, Issue4, June 2018, \#Art.216, pp59-66

\section{Introduction}

As per the ongoing statistics contemplate, it has been discovered that there has been quick development of the populace around two and half circumstances amid the most recent fifty years. In any case, urban India has expanded about five times. In 2001, 306.9 million Indians $(30.5 \%)$ were living in about 3,700 towns and urban communities spread the nation over, and it is relied upon to increment to more than 400 million and 533 million in 2011 and 2021 separately. The real worry for India's urban and town organizers for effective urban improvement is the significant issue of persistent development of the populace. The newest innovation, for example, flying and in addition, satellite based computerized framework must be utilized to watch out for the developing populace. These computerized 


\section{International Journal of Advanced Multidisciplinary Scientific Research (IJAMSR) ISSN:2581-4281}

systems allow us to gather part of physical information effortlessly [1], with rapid and on dreary premise, and together with the assistance of GIS it empowers us to investigate the information spatially, offering new conceivable outcomes of producing different alternatives, in this manner streamlining the entire arranging and advancement process. One of the primary uses of GIS is urban planning. Spatial database and demonstrating device are utilized by the Urban Planners with the assistance of GIS. GIS applications may contrast as per levels, stages and segments. Because of the ease of use, low value equipment and capacities gave by GIS programming made it extremely well known in the ongoing years. GIS has turned into an essential segment of arranging emotionally supportive networks. Mix of GIS with arranging models, representation, and the Internet will make GIS more helpful to urban arranging. The significant issues in utilizing GIS for urban arranging are not the specialized issues, but rather the absence of information [2], changes in authoritative and staffing.

Geographic Information System has acquired a consistently expanding significance and it has been broadly acknowledged as a basic leadership device in urban arranging. Geographic Information System enables us to get to vast volumes of information and data. It likewise permits in manipulating data, keeping in mind the end goal to choose, refresh [6], consolidate, and model and show the data. Numerous nations have contributed vast totals of cash for securing propelled PC for building up their urban communities and have confronted dissatisfaction regardless of the upsides of a GIS in arrive utilize arranging and management [3]. Particularly in circumstances where there was close to nothing or deficient comprehension of PC based frameworks such venture have been to a great extent utilized. The utilization of innovations, for example, GIS has been dealt with by a need of skilled faculty, deficient technological structures, and trouble in transferring information to end-clients and by inadequate global collaboration to support local research and enhance the data flow [4]. GIS has turned out to be an extremely valuable and groundbreaking apparatus for urban arranging and administration. The requirement for successful urban arranging proceeds to grow as the world advances towards improvement [7], the issue of urban arranging turns out to be more confounded. In the present innovation, we center around urban arranging as opposed to adjust the framework that was manufactured quite a while prior. There can be some circumstance soon where we should stop urbanization which implies that we will dependably attempt to fit into the already settled framework. For instance, Global warming, deforestation

The utilization of GIS in Urban Planning GIS was created in the late 1960s be that as it may, because of its mind-boggling expense of equipment and constrained abilities in the product it was infrequently utilized as a part of the early days. In the underlying phases of advancement programming frameworks concentrated on PC mapping with couple of systematic capacities. The most intense programming around then was lattice based (e.g. IMGRID). In ongoing years the costs of equipment, PC stockpiling, and peripherals, diminished significantly and has made GIS more reasonable, less tedious and more serviceable [4]. GIS is one the intense modernized frameworks which incorporate the information from different sources and aides in settling on choices adequately for urban arranging.GIS serves both as a database and as a tool steels for urban arranging and 
improvement. Using the Geo-social model spatial and literary information can be put away and got from database. Current GIS programming frameworks bolster productive information recovery, stockpiling, question, and mapping. Current GIS framework empowers organizers to extricate information from their databases and info them to another displaying and spatial scientific program [5]. Geological data can be utilized to settle on successful arranging choices which can be made by consolidating information from databases, studies. GIS acts as a tool stash which enables organizers to perform spatial analysis. It likewise empowers the organizers to utilize Geo-handling capacities, for example, delineate, availability estimation, and buffering.

Land is a profitable asset that continually acknowledges in esteem. Because of the absence of innovation in the previous years, it is difficult to accomplish the information and data which we can assemble today. The world today is progressing quicker than at any other time with enormous a wide margin made in the field of innovation. So as to accomplish our targets we require exceedingly particular GIS gear, propelled programming's and enough gifted work. Urban arranging and administration is a perplexing assignment [8]. One can't finish the urban arranging and administration without the utilization of a groundbreaking scientific apparatus like GIS. GIS discovers its utilization in urban arranging as a logical and demonstrating apparatus [6]. It can be connected to an extensive variety of tending to issues identified with information base structures, basic and complex expository models alike. GIS can be valuable for directing an attainability investigation of an area for a particular reason, e.g. discovering the appropriateness of an area for the development of an extension or dams. GIS encourages us in checking the spatial information. Plausibility investigation of considerably littler structures like schools, universities, play areas and healing facilities is basic and can be effectively directed with the assistance of GIS. In the regions where the assortment of outlines or elective designs are required, the utilization of GIS can be joined with particular and more modern types of gear to deliver better yields [7].

Numerous advantages in utilizing GIS in urban arranging are as per the following:

- Improved mapping - GIS gives better access to maps. It causes us by giving enhanced guide cash. It empowers to demonstrate a specific topic associated with a particular geographic territory which is otherwise called topical mapping and it likewise has less capacity cost.

- Efficient recovery, Data and data can be effectively recovered by making the utilization of GIS which is exceptionally helpful for urban arranging and advancement.

- 'Consider the possibility that' situations Faster and broader access to the kinds of topographical data essential to arranging and the capacity to investigate a more extensive scope of various situations.

- Improved examination GIS causes us to break down the information very proficiently by making the utilization of cutting edge innovation 


\section{Advanced Multidisciplinary Scientific Research (IJAMSR) ISSN:2581-4281}

- User benevolent GIS has an exceptionally intuitive interface and it gives every one of us the apparatuses fundamental for urban arranging and improvement. It empowers better correspond to the general population and staff.

Nature of administration It gives enhanced nature of administrations, for instance speed access to data for arranging, advancement and application handling.

\section{Approach}

The accompanying approach was embraced in the present investigation,

- The base guide of the examination region was readied utilizing existing guide which made plotting the information on the maps less demanding.

- Using GIS system, the topic maps have been composed and arranged to demonstrate a specific topic associated with a particular geographic region.

- Plotting, Digitizing, Editing and marking the different topic maps, Integration and Preparation of determined maps utilizing GIS programming.

\section{Fundamental Requirements for Urban Planners}

Aside from utilizing mapping systems which incorporate expansive scale detail and quantitative portrayal of help showed by form lines. Organizers gather data on existing area usage and their intermittent updating and observing utilizing GIS and Remote Sensing. By making the utilization of appropriate system and philosophy similar information items can be utilized to:

- Monitoring and refreshing the topic maps on normal premise It is simple for urban organizers to recognize ghetto zones as GIS continues checking and refreshing the framework

- Study of transportation framework utilized as a part of the current geological region

- By making the utilization of topical maps it empowers urban organizers to isolate diverse catchment zones

- Analyzing the empty space is less demanding for Urban Planners

The examination and outline depend on significant writing, pardon laws, insights from the City Statistics Institute made in a couple of years back. Diverse topical maps for specific topographical areas, different ground breaking strategies and recreation overhauling plans has been presented, field studies, information from concerned specialists and from the reports composed by these experts and associations. The urban organizers must make utilization of following parameters amid examination of the topographical region which are recorded underneath:

- Population data gave by the evaluation to the specific land region

- Depending upon the territory number of story's can be chosen 
Advanced Multidisciplinary Scientific Research (IJAMSR) ISSN:2581-4281

- Planning ought to be appropriately done as such that adequate open administrations are given to the general population

- Public administrations must be close-by

Urban Planning and improvement GIS finds an essential part in the field of Urban Planning and advancement. The highlights of GIS which makes it critical in the Urban Planning and advancement are as per the following:

- Multiple information can be entered and coordinated;

- The framework can keep up information consistency;

- Updating of information can do every effortlessly and proficiently;

- Data can be put away and recovered in an exact way.

Integration of spatial and different sorts of data should be possible utilizing GIS inside a solitary framework. Examining geological information should be possible in an easy to understand structure which is given by GIS. Topographical Information System enables us to control and show land learning by putting maps and different sorts of spatial data into advanced structures. Because of the coordinated innovation of GIS and Remote Sensing it has turned out to be exceptionally well known and is generally utilized as a part of various applications. These two advances are correlative, as they are just variations of the computerized spatial information. GIS and Remote Sensing have turned out to be indistinguishably connected in numerous application fields. In the previous two decades the utilization of spatial data, GIS, Remote Sensing data has been enormously enhanced and which assumes an indispensable part in the field of urban arranging and improvement. Spatially exact and auspicious data ashore utilize and changing example is required for urban arranging and improvement. Checking is imperative, as it furnishes the organizers and decision makers with required data about the present condition of advancement and the further changes that can happen. Remote detecting and Geographical Information framework (GIS) gives essential apparatuses which can be connected with the investigation in the region and additionally at the city level.

Remote detecting and GIS is the accumulation of data around a question or marvel without reaching the protest. In current utilization, the term by and large alludes to the utilization of airborne sensor innovations to distinguish and group questions on Earth (both at first glance, and in the air and seas) by methods for engendered signals (e.g. electromagnetic radiation transmitted from air ship or satellites).

There are two primary sorts of remote detecting which are as per the following:

\section{Passive remote detecting:}

The vitality required by the detached, remote detecting is gathered by sensors which are given by the earth. Reflected daylight is the most widely recognized wellspring of radiation estimated by inactive sensors. Cases of uninvolved remote sensors incorporate film photography, infrared, charged coupled gadgets, and radiometers. 


\section{International Journal of Advanced Multidisciplinary Scientific Research (IJAMSR) ISSN:2581-4281}

\section{Active remote detecting:}

Dynamic remote detecting gives the method for transmitting vitality which enables the vitality to be considered the adjacent condition and after that remembers the vitality utilizing sensors. RADAR and LiDAR are cases of dynamic remote detecting where the time delay among emanation and return is estimated, building up the area, speed and heading of a protest.

\section{Remote Sensing, GIS applications in urban arranging}

Remote detecting makes it conceivable to gather information on perilous or difficult to reach zones. Remote detecting applications incorporate monitoring deforestation in territories, for example, the Amazon Basin, cold highlights in Arctic and Antarctic areas, and profundity sounding of beach front and sea profundities. Remote sensing collects the information effectively starting from the earliest stage likewise reduces the cost. Remote Sensing ensures that in the process of gathering information from condition the zones or objects are not aggravated. Orbital stages gather and transmit information from various parts of the electromagnetic range, which in conjunction with bigger scale aeronautical or ground based detecting and examination, furnishes analysts with enough data to screen patterns, for example, other normal long and here and now wonders. Other uses of remote detecting incorporates distinctive zones of the earth sciences, for example, normal asset administration, farming fields, for example, arrive use and protection, natural life, and national security and overhead, ground based and standoff accumulation on fringe zones. By satellite, flying machine, shuttle, float, ship, and helicopter pictures, information is made to break down and analyze things like vegetation rates, disintegration, contamination, ranger service, climate, and land utilize. These things can be mapped, imaged, followed and watched utilizing remote detecting. The procedure of remote detecting is additionally useful for city arranging and improvement, logical examinations and investigation, military perception and gathering information from surface highlights of the Earth.

\section{Utilization of Aerial Photography in Urban Planning}

Urban arranging and advancement makes utilization of aeronautical photos for observing and examination. In India, city arranging and improvement has been to a great extent bound to aeronautical photography. It is being utilized for age of base maps and other topic maps for urban zones and development. It has additionally turned out to be taken a toll, time compelling and solid. Elevated photography gives data relating to arrive highlights, arrive, utilize, developed regions, city foundation, physical parts of condition and so on. Elevated photography utilizes different kinds of cameras and sensors, high contrast, shading, shading infrared. In view of security concerns identified with airborne photography, the utilization of photogrammetric methods was bound to smaller urban communities. Flying photos give data that can fundamentally enhance the adequacy of city and town, arranging and administration in India. They are likewise moderately low in cost, exact, solid and can be gotten on wanted scale. Be that as it may, they are not helpful in substantial metropolitan zones because of security issues. For getting exact land use data the accompanying focuses ought to be considered: 


\section{International Journal of Advanced Multidisciplinary Scientific Research (IJAMSR) ISSN:2581-4281}

- Imagery characteristics: Characteristics of symbolism incorporates size of the photography, settling intensity of the film, changing complexity and sharpness, wave band used, format of the picture.

- Land utilizes characteristics: This incorporates connection amongst frame and capacity, different use of land, sort of land, the measure of ground control, any change since symbolism was gotten.

- User characteristics: understanding aptitudes of individual organizer, utilization of stereoscopic techniques which makes impression of profundity a strength as the photos are taken from various points.

\section{Use of Remote Sensing}

Remote Sensing innovation may prompt development in the planning process in different ways:

(I) Due to the utilization of digitization in making base maps for arranging sudden changes in base maps or design designs can be refreshed at general interims and so on. Superimposition of any two advanced maps which are on two unique scales is attainable. Because of the ability of advanced maps encourages inclusion of crisp study or adjusted maps into existing base maps. So also superimposition of income maps on base maps with sensible precision is of extraordinary favorable position contrasted with physically done tasks.

(ii) Since all the data and maps are accessible in advanced configuration, joining different layers of information and data about a component from satellite symbolism, arranging maps and income maps are achieved with the assistance of different picture handling programming like ERDAS Imagine, ENVI and PCI Geomatica, ILWIS. Such super forced maps in GIS programming like Map data, Arc View, Auto CAD Map and Arc GIS and so on give profitable data to arranging, advancement, usage and administration of urban zones.

(iii) The methods utilized by Remote Sensing are to a great degree accommodating for recognizing change location examination and determination of locales for particular offices, for example, healing facility, play areas, schools, universities, eateries, strong waste transfer and industry. An endeavor has been made here to exhibit the possibilities of remote detecting strategies in base mapping, arrive, utilize and arrive, cover mapping, urban change identification and mapping, urban framework and utility mapping, urban populace estimation, administration and so forth

\section{Issues and Issues}

Numerous issues emerge when Geographical Information System (GIS) is utilized amid elucidation of various urban land utilize, arrive cover highlights. While making the utilization of GIS in breaking down topographical zone another issue which can emerge is that a portion of the structures could possibly be recognized. Despite what might be expected, a large number of the circumstances singular houses can't be always been distinguished, the correct position or limit of the houses and city squares can regularly be identified; sometimes it can be deciphered through satellite pictures. In this specific situation, GIS and urban remote detecting must have the capability to give planners with certain key, informational collections that are pertinent to urban examinations like area and degree of urban territories, the essential framework and 
transportation arrangements, capacity to screen changes in these highlights after some time and distance.

\section{Conclusion}

- Remote Sensing and GIS can give us hearty outcomes by extricating urban land cover data.

- In created and creating nations the utilization of GIS assumes a vital part. In the previous couple of years numerous arranging divisions have moved their concentration from mapping frameworks to GIS. $\square$ Due to ease of use and number of capacity giving ability has made GIS extremely well known.

- The astounding decline in the costs of equipment parts has made GIS reasonable to the end-client and an agreeable instrument for arranging.

- Recent advances and joining of GIS with Geospatial, representation, and the Internet will make GIS more helpful to urban arranging and improvement. Possibilities of remote detecting methods in base mapping, arrive, utilize and arrive, cover mapping, urban change discovery and mapping, urban foundation.

References:

1. Dadi, Sanyasinaidu. "USE OF GIS IN HYDROLOGICAL INVESTIGATIONS." INTERNATIONAL JOURNAL OF MULTIDISCIPLINARY ADVANCED RESEARCH TRENDS.(2015): Web.<https://www.researchgate.net/publication/321 069487_USE_OF_GIS_IN_HYDROLOGICAL_IN VESTIGATIONS>.

2. Dadi, Sanyasinaidu. "An Importunate Role of GIS in Indian Retail Industry." MAT Journals-Journal of Remote Sensing GIS \& Technology. (2017): Web. $<$ http://www.matjournals.in/index.php/JORSG T/article/view/2110>.
3. Dadi, Sanyasinaidu. "Remote Sensing and Geographic Information System for Jungle Administration." MAT -matjosurnals-JOURNAL OF REMOTE SENSING GIS \& TECHNOLOGY (2017):

Web. <http://matjournals.in/index.php/JoADC/article /view/2128>.

4. Dadi, Sanyasinaidu. "GIS and Remote Sensing as Tool to Develop Applications for Natural Resource Management." MAT -matjournals-JOURNAL OF REMOTE SENSING GIS \& TECHNOLOGY. (2017):

Web.<http://www.matjournals.in/index.php/JORSG T/article/view/2101>.

5. Dadi, Sanyasinaidu. "GIS and Remote Sensing For Site Specific Farming Area Mapping." MATmatjournals-Journal of Analog and Digital Communications. (2017):

Web.<http://matjournals.in/index.php/JoADC/article /view/2126>.

6. Dadi, Sanyasinaidu. "UNDERSTANDING THE CONCEPT OF VIRTUAL GLOBE FOR A GIS PERSONNEL." INTERNATIONAL JOURNAL OF MULTIDISCIPLINARY ADVANCED RESEARCH TRENDS. (2015):

Web. <http://ijmart.in/PreviousIssues/Sep2015/4.pdf $>$

7. Dadi, Sanyasinaidu. "GIS Applications to Smart Cities." International Journal of Advanced Multidisciplinary Scientific Research(IJAMSR) Volume 1,Issue 1, February (2018).

8. Dadi SanyasiNaidu, and Peddada Jagadeeswara Rao. "Study on Sustainable Management of Groundwater Resources in Greater Visakhapatnam Municipal Corporation, Visakhapatnam District, India-A Hydro Informatics Approach.” Springer Series in Geomechanics and Geoengineering Proceedings of International Conference on Remote Sensing for Disaster Management, 2018, pp. 719728., doi:10.1007/978-3-319-77276-9_64.

9. http://www.gislounge.com/gis-urbanplanning/

10. https://www.esri.com/library/bestpractices/u rbanregional-planning.pdf.

11. http://www.esri.com/industries/planning

12. http://geospatialworld.net/paper/application/ ArticleView.aspx?aid=1420\#

13. http://www.giminternational.com/issues/articles/id4 24Benefits_of_GIS_in_Urban_Planning.html

14. http://gisp.asia/blog_gisp/?page_id=332

15. http://www.gisdevelopment.net

16. http://geospatialworld.net/Paper/Technology /ArticleView.aspx?aid=25039

17. Mr. SujitPavaskar - Currently pursuing Master's in Computer Application (Third year) at ASM's Institute of Management \& Computer Studies (IMCOST), Mumbai.

18. Mr. Deepak Rajaram - Currently pursuing Master's in Computer Application (Third year) at ASM's Institute of Management \& Computer Studies (IMCOST), Mumbai. 